\title{
Splenectomy: Does it help in Patients with Thalassemia Major
}

\author{
Abdul Salam Memon, Riaz Memon, Agha Taj Muhammad, Syed Asad Ali, \\ Akmal Jamal Siddiqui
}

\begin{abstract}
OBJECTIVE: To determine the benefits of elective splenectomy in selected patients with thalassemia major.

STUDY DESIGN: Prospective descriptive study.

PLACE OF STUDY: Liaquat University Hospital Jamshoro.

DURATION OF STUDY: July 2014 to June 2015.

PATIENTS AND METHODS: 27 selected patients of Thalassemia major were evaluated after open elective splenectomy via midline incision for the benefits achieved post operatively.

RESULTS: Out of 27 patients $19(70.3 \%)$ were male and $08(29.6 \%)$ were female, age ranges from $5-10$ years with a mean age of 7 years. Out of 27 patients, 25 patients $(81.48 \%)$ had a uneventful recovery, only 2 patients $(7.4 \%)$ developed post-operative complications. No mortality was observed in this series. Post-operative long term maintenance of adequate hemoglobin and improved quality of life was observed in $26(96.29 \%)$ patients. Only $1(3.7 \%)$ patient who developed postoperative incisional hernia was not satisfied with the procedure.

CONCLUSION: We conclude that splenectomy is a safe and beneficial procedure in selected patients of thalassemia major.
\end{abstract}

KEY WORDS: splenectomy, Thalassemia major, benefits.

This article may be cited as: Memon AS, Memon R, Muhammad AT, Ali SA, Siddiqui AJ. Splenectomy: Does it help in Patients with Thalassemia Major. J Liaquat Uni Med Health Sci. 2017;16 (01):20-3.doi: 10.22442/jlumhs. 171610500

\section{INTRODUCTION}

Thalassemia was first reported by Cooley from USA in certain Mediterranean origins and is termed Cooley's or Mediterranean anemia. An alternate term is thalassemia (a Greek word) which means "sea in the blood"1,2. Thalassemia result from an inherited defect in genetic information coding, with consequent failure of manufacture of the Beta chain so that abnormal hemoglobin is produced ${ }^{3,4}$. The defective RBC's have a very short life less then 120 days and readily hemolyzed when squeezed through the spleen, giving rise to severe hemolytic anemia ${ }^{5}$.

Current management in Pakistan includes repeated blood transfusion from Non thalassemia donors, oral / injectable iron chelating agents (as iron from hemolyzed RBC can reach toxic levels and get deposited in liver \& heart), open or Laparoscopic splenectomy and Bone Marrow transplantation. Many thalassemia patients still require splenectomy in selected cases ${ }^{6}$.

In the developed world more effective and less laborious treatment are in use that includes pharmacological induction of fetal hemoglobin, the use of artificial blood substitutes and research into gene therapy ${ }^{7,8}$.

There are many published papers on the benefits achieved in thalassemia patients after splenectomy; we assessed benefits of splenectomy with regard to safety of the procedure, reduction in the rate of blood transfusion, maintenance of adequate hemoglobin and as well as patients quality of life.

\section{PATIENT \& METHODOLOGY}

Counseling of the parents was done before surgery regarding post splenectomy sepsis and informed consent was obtained. Quality of life was assessed by a questionnaire before and 06 months after surgery. During period of the study, 27 patients of Thalassemia Major were operated electively for open splenectomy. The age of patients ranged from 05 years to 10 years, with 19 male \& 08 female children. They were investigated for base line investigations and for anesthesia fitness. The most frequent indication for splenectomy was massive splenomegaly, followed by neutropenia and frequent blood transfusion for more than 4 in a month. Patients with minor and intermediate thalassemia, sickle cell or other blood disorders were excluded from the study.

Pre-operatively patient's hemoglobin was maintained between $8-10 \mathrm{gm} / \mathrm{dl}$ and 2 weeks before surgery vaccination against for pnemococcus, meningococcus and $\mathrm{H}$. Influenza was done. Splenectomy performed by open surgical technique. Left sub-costal incision was made to open the abdomen, peritoneum was opened in the line of incision and splenic artery and vein were 
identified and ligated. The spleen was retracted to ligate splenocolic, lienorenal and splenophrenic ligaments between ligatures. Stomach was retracted, short gastric arteries identified and ligated at gastrosplenic ligament, Finally gastrosplenic ligament is also incised between ligatures. Spleen was removed and haemostasis achieved with particular attention to splenic hilum, diaphragmatic surface and colonic surface.

Results were evaluated for post operative complications and post Splenectomy quality of life. The parents were educated about possibility of post splenectomy sepsis, and on every follow up visit Hemoglobin estimation done.

\section{RESULTS}

Out of 27 patients $19(70.3 \%)$ were male $08(29.6 \%)$ were female who underwent elective splenectomy during the study period. The age ranged from 5-10 years with an average of 7 years. The hospital stay was ranges between 2-10 days. 22(81.48\%) patients had a uneventful postoperative recovery and they were discharged on $2^{\text {nd }}$ postoperative day. Three $(11.1 \%)$ patients had a longer hospital stay between 5 to 10 days. No mortality was recorded in this series. (Table I).

Although only 2 patients $(7.4 \%)$ developed postoperative complications, however $5(18.5 \%)$ complications were observed in these 2 patients. One female (3.7 $\%)$ patient developed secondary hemorrhage was re-explored and bleeding was secured. Another male $(3.7 \%)$ patient also developed secondary hemorrhage was re-explored and bleeding was secured. Same patient developed acute dilatation of stomach (3.7\%), which was managed conservatively by NG tube. Later the same above patient also developed wound infection $(3.7 \%)$ and incisional hernia $(3.7 \%)$ as late complication. He was operated, after one year, for repair of incisional hernia using on-lay prolene mesh. Patient who developed secondary hemorrhage was discharged on $5^{\text {th }}$ postoperative day and the other patient who developed multiple postoperative complications on $10^{\text {th }}$ day. Pancreatic injury, Pulmonary Atelectasis, subphrenic abscess and post splenectomy sepsis (OPSI) were not observed in our study. (Table II).

Quality of life was assessed in all 27 patients regarding the impact of splenectomy on the general improvement of quality of life through a questionnaire. The indications for splenectomy were high frequency of blood transfusion and poor quality of life. After splenectomy we observed dramatic increase in hemoglobin level between 8-10 gm/dl. Most of the patients have a decrease in the blood transfusion requirement; from 4-5 times in a month to a single blood transfusion per month. Improved hemoglobin results in less fatigue and less bothering for blood transfusion and donors search, traveling time and transfusion time for the family members. The physical activities of the patient improve due to removal of huge size spleen. The cost of iron chelation also decreases, some patients start their schooling with improve attendance and academics. Out of 27 patients, only 10 (37.03\%) urban patients attended school prior to surgery. All these urban patients had a definite improvement in attendance and academic performance in school. We also observed definitive improvement in indoor and outdoor activities of all urban and rural patients probably due to elimination of abdominal discomfort \& heaviness after splenectomy.

Only $01(3.7 \%)$ patient who developed incisional hernia does not report any improvement in outdoor physical activity for a year post-operatively until he had a mesh repair. He had a long term discomfort with an abdominal binder due to a large incisional hernia. $26(96.29 \%)$ patients and their parents were satisfied with the outcome / benefits due to overall improved quality of life. (Table III).

TABLE I: PATIENTS DEMOGRAPHICS $(n=27)$

\begin{tabular}{|l|c|c|}
\hline \multicolumn{1}{|c|}{ Demographics } & No. of Patients & $\%$ \\
\hline Male & 19 & 70.3 \\
\hline Female & 08 & 29.6 \\
\hline Age range & 5-10 years \\
\hline Mean & \multicolumn{2}{|c|}{7 years } \\
\hline Hospital stay range & $2-10$ days \\
\hline Average hospital stay & 2 days $(81.48 \%)$ \\
\hline Morbidity & \multicolumn{2}{|c|}{$7.4 \%$} \\
\hline Mortality & 00 \\
\hline
\end{tabular}

TABLE II:

POSTOPERATIVE COMPLICATIONS ( $n=27)$

\begin{tabular}{|l|c|c|}
\hline \multicolumn{1}{|c|}{ Complications } & No. of patients & $\%$ \\
\hline Early & & \\
a) Secondary hemorrhage & 02 & 7.4 \\
b) acute dilatation of stom- & 01 & 3.7 \\
ach & 01 & 3.7 \\
c) Wound Infection & 00 & 00 \\
d) Pulmonary Atelectasis & 00 & 00 \\
e) sub phrenic abscess & 00 & 00 \\
f) Pancreatic injury & & \\
\hline Late & & \\
a) Incisional hernia & 01 & 3.7 \\
b) post splenectomy sep- & 00 & 00 \\
sis (OPSI) & & \\
\hline Total & 05 & 18.5 \\
\hline
\end{tabular}


Abdul Salam Memon, Riaz Memon, Agha Taj Muhammad, Syed Asad Ali, Akmal Jamal Siddiqui

\begin{tabular}{|c|c|c|}
\hline $\begin{array}{c}\text { Benefit } \\
\text { achieved / (QOL) }\end{array}$ & $\begin{array}{c}\text { Pre-operative } \\
\text { Status }\end{array}$ & $\begin{array}{c}\text { Post-operative } \\
\text { Status }\end{array}$ \\
\hline $\begin{array}{l}\text { Blood Transfusion } \\
\text { Frequency }\end{array}$ & $\begin{array}{l}4 \text { - } 5 \text { units / per } \\
\text { month }\end{array}$ & $\begin{array}{l}1-1.5 \text { unit / per } \\
\text { month }\end{array}$ \\
\hline Hemoglobin Level & $6-7$ gram $\%$ & $8-9$ gram \% \\
\hline \multirow{5}{*}{ QOL } & $\begin{array}{l}\text { Search for } 4 \text { - } 5 \\
\text { healthy donors / } \\
\text { per month }\end{array}$ & $\begin{array}{l}\text { Search for only } 1 \\
\text { healthy donor / } \\
\text { per month }\end{array}$ \\
\hline & $\begin{array}{l}\text { More traveling and } \\
\text { multiple } \\
\text { transfusions }\end{array}$ & $\begin{array}{l}\text { Less traveling and } \\
\text { single transfusion }\end{array}$ \\
\hline & $\begin{array}{l}\text { Chelation cost and } \\
\text { dangers of iron } \\
\text { deposition }\end{array}$ & $\begin{array}{l}\text { Less chelation } \\
\text { cost and dangers } \\
\text { of iron deposition }\end{array}$ \\
\hline & $\begin{array}{l}\text { No / minimal } \\
\text { physical activity } \\
\text { only at home }\end{array}$ & $\begin{array}{l}\text { Resume outdoor } \\
\text { physical activity }\end{array}$ \\
\hline & $\begin{array}{l}\text { No education / no } \\
\text { schooling }\end{array}$ & $\begin{array}{l}\text { Start schooling } \\
\text { with improves } \\
\text { academics }\end{array}$ \\
\hline
\end{tabular}

\section{DISCUSSION}

The splenomegaly is known to occur in thalassemia major patients causing excessive destruction of abnormal RBCs and excessive iron over load deposition in liver and heart ${ }^{8}$. Splenomegaly further increases transfusion requirement hence these patients are benefited from splenectomy ${ }^{1,2}$. The struggle against thalassemia has dramatically increased against the past few years across the world. Advance modalities of treatment includes bone marrow transplantation, peripheral blood stem cells transplantation, cord blood stem cells transfusion, gene therapy and stimulation of fetal hemoglobin ${ }^{4,5,7}$. Fortunately in Pakistan bone marrow transplantation has also been started. In children until 5 years of age weight of spleen is about 50 grams but in splenomegaly with thalassemia major it weights about $600-1000$ grams or more, resulting in abdominal discomfort and heaviness hence restricting their physical activities. After splenectomy frequency of blood transfusion decreases remarkably with decrease financial, physical and psychological burden on patients and their family. The patients are able to maintain adequate hemoglobin with fewer incidences of iron loading and deposition resulting in improve survival $^{5}$. Splenectomy also promotes physical activities and children already in schools with improved attendance and academics.

Splenectomy is performed in children for various blood disorders like Idiopathic Thrombocytopenic purpura

etc $^{3}$. It has been documented with minimal postopera-

tive complications and overall improved quality of life of patients and their attendance. Due to decrease in the frequency of blood transfusions hazards of Iron deposition in liver \& heart also decreases. Hence splenectomy is beneficial and justified with improve survival rate in these patients.

We performed 27 splenectomies during the period of study. We had no mortality in our study. However, Saha ${ }^{8}$ et al \& Hussain ${ }^{9}$ et al reported $5 \%$ \& $3.5 \%$ mortality in their studies.

We report five post-operative complications i.e secondary hemorrhage, Acute dilatation of stomach, wound infection \& incisional hernia in only 2 patients $(7.4 \%)$. However, we did not observed other complications like pancreatic tail injury, sub phrenic abscess or in long term OPSI. These results are in sharp contrast to other series on the subject ${ }^{2,10}$. Saha et al in his series reported two postoperative complications that includes wound infection $(10 \%)$ \& secondary hemorrhage $(5 \%)$ 8 , while Hussain et al in series of 28 patients did not report any postoperative complication ${ }^{9}$.

Regarding the post splenectomy quality of life $96.2 \%$ of our patients \& their family members were satisfied with the procedure in terms of improved physical activities due to reduced abdominal distension, discomfort and heaviness\& maintenance of adequate $\mathrm{HB} \%$ resulting in decrease frequency of blood transfusion and visits to thalassemia center. These results are in sharp contrast to other series reported ${ }^{11-13}$.

$\mathrm{Saha}^{8}$ et al also reported an improvement in quality of life due to a significant reduction in number of blood transfusion after the procedure.

Similarly, Hussain ${ }^{9}$ et al also reported improvement in quality of life in his $21(75 \%)$ patients in term of physical activity with improve school attendance \& participation in outdoor sports.

\section{CONCLUSION}

Splenectomy is safe and beneficial in selected cases of thalassemia major. It decreases frequency of blood transfusion, promotes more physical activities including schooling. Overall quality of life of patients and their family members improves after splenectomy and should not be delayed if indicated.

\section{REFERENCES}

1. Porecha MM, Udani D, Mehta V, Gami A. Splenectomy In Management Of Thalassemia Major - A Boon For The Little Angel. The Internet Journal of Surgery. 2009;24(1):1-11.

2. Bolt JD, Schoneboom BA. Operative Splenectomy for Treatment of Homozygous Thalassemia major in Afghan children at a US Military Hospital. AANA Journal 2010, 78(2), 129-133. 
3. Jain $P$, Kundal $R$, Dogra $N$, Bharadwaj $A$. Anaesthetic Management for Splenectomy in Thalassemia Minor Complicated With SLE and Hypothyroidism. IJAR. 4(4):1-2.

4. Pecorari L, Savelli A, Cuna CD, Fracchia S, Borgna-Pignatti $C$. The Role of Splenectomy in Thalassemia major, An update. Acta Pediatrica Mediterranea, 2008, 24: 57-60.

5. Piga A, Serra $M$, Longo $F$, et al. Changing patterns of splenectomy in transfusion dependent thalassemia patient. Am J Hematol. 2011;86 (9):808-10.

6. Bisharat N, Omari H, Lavi I, Raz R. Risk of infections and death among post splenectomy patients. J Infect. 201;43( 3):182-6.

7. Cappellini MD, Robbiolo L, Bottasso BM, et al. Venous Thromboembolism and Hypercoagubility in Splenectomized patients with Thalassemia Intermedia. Br J Haematol. 2000;111(2):467-73.

8. Saha R, Misra R, Saha I, Health related quality of life and its predictors among Bengali Thalasssemic children admitted to a tertiary care hospital. India J Pediatr. 2015;82(10):909-16. doi: 10.1007/s12098-014-1670-6.

9. Hussain S, Anwer A, Ahmad A, Jaffery S, Improved quality of life in post splenectomized thalassemic patients Pak J Surg 2011; 27(2): 83-86.

10. Gupta N, Kaur S, Goila A, Pawar M. Anaesthetic management of a patient with Eisenmenger syndrome and $\beta$-thalassemia major for splenectomy. Indian J Anaesth. 2011;55(2):187-9.

11. Al-Salem AH. Is splenectomy for massive splenomegaly safe in children? Am J Surg. 1999 Jul; 178(1): 42-5.

12. Cohen A, Gayer R, Mizanin J. Long-term effect of splenectomy on transfusion requirements in thalassemia major. Am J Hematol. 1989;30: 254-6.

13. Ammar SA, Elsayh KI, Zahran AM, Embaby M. Splenectomy for patients with $\beta$-thalassemia major: long-term outcomes. Egypt J Surg. 2014. 33:232-6.

AUTHOR AFFILIATION:

Dr. Abdul Salam Memon

Senior Registrar, Department: Surgery

Liaquat University of Medical \& Health Sciences

(LUMHS), Jamshoro, Sindh-Pakistan.

Dr. Riaz Memon

Senior Registrar, Department: Surgery

LUMHS, Jamshoro, Sindh-Pakistan.

Dr. Agha Taj Muhammad

Assistant Professor, Department: Surgery

LUMHS, Jamshoro, Sindh-Pakistan.

Dr. Syed Asad Ali (Corresponding Author)

Associate Professor, Department: Surgery

LUMHS, Jamshoro, Sindh-Pakistan.

Email: sasadalishah@gmail.com

Prof. Akmal Jamal Siddiqui

Department of Surgery

Bilawal Medical College, Jamshoro, Sindh-Pakistan. 